\title{
Karirí como família linguística Macro-Jê no Nordeste do Brasil ${ }^{1}$
}

\author{
Karirí as a Macro-Jê Linguistic Family \\ in Northeastern Brazil
}

Aryon Dall'Igna Rodrigues

DOI: https://doi.org/10.26512/rbla.v11i1.26441

Recebido em janeiro/2019 e aceito em março/2019.

\section{Resumo}

A família linguística Karirí, proposta primeiramente por Adam (1896), foi incluída no tronco Macro-Jê desde Mason (1950). Enquanto a primeira inclusão foi baseada sobretudo em algumas semelhanças lexicais, Rodrigues (1999) apresentou alguns traços morfológicos e sintáticos de concordância tipológica com outras famílias incluídas no mesmo tronco. Neste estudo, discuto a consistência de todos esses elementos para considerar a família Karirí como membro do tronco Macro-Jê.

Palavras-chave: Família Karirí. Tronco Macro-Jê. Correspondências lexicais. Correspondências morfológicas. Correspondências sintáticas.

\begin{abstract}
The Karirí linguistic family, first proposed by Adam (1896), has been included in the Macro-Jê stock since Mason (1950). Whereas the first inclusions were based on some lexical similarities, Rodrigues (1999) presents some morphological and syntactical features agreeing typologically with other families included in the stock. I will discuss the above criteria as the foundations for considering the Karirí family a putative member of the Macro-Jê stock.
\end{abstract}

Keywords: Karirí family. Macro-Jê stock. Lexical correspondences. Morphological correspondences. Syntactic correspondences.

\section{Família linguística Karirí}

A família linguística Karirí, como conjunto de línguas geneticamente aparentadas e independentes de outras famílias já reconhecidas, foi estabelecida primeiro, há pouco mais de cem anos, pelo linguista francês Lucien Adam: "os linguistas se convencerão facilmente que a gramática e o léxico do Karirí constituem uma espécie, ao mesmo título que a gramática e o léxico quer do Caribe, quer do Tupi, quer do Maipure." (Adam 1897:IV, trad. de ADR). A primeira proposta de um tronco linguístico constituído por diversas famílias e correspondendo aproximadamente ao tronco Macro-Jê deve-se a Čestmír Loukotka em seu trabalho de 1942, "Klassifikation der südamerikanischen Sprachen”. Seu tronco linguístico Tapuya-Žé (Tapuya-Žé-Sprachstamm)

${ }^{1}$ Acervo Aryon Dall’Igna Rodrigues - Fundação Aryon Dall’Igna Rodrigues. 
compreendia as famílias Žé, Opaie, Kaingán, Coroado, Mašakali, Patašo, Botokudo e Kamakan, tendo sido a família Karirí (Kairiri-Sprachfamilie) considerada independente desse tronco (Loukotka 1942:4-6). O nome MacroJê ("Macro-Ge") foi introduzido em 1950 por Joseph Alden Mason em sua grande revisão das línguas sul-americanas para o Handbook of South American Indians, para designar um grande grupo de famílias só em parte coincidente com o tronco Tapuya-Žé de Loukotka (que Mason ainda não conhecia) e compreendendo as seguintes nove famílias: Ge, Caingang, Camacán, Mashacalí, Purí, Patashó, Malalí, Coropó e Botocudo (Mason 1950:287-288). A família Karirí ("Caririan") continuou sendo tratada como independente (Mason 1950:286-287). Já Joseph Greenberg, que forjou o conceito “Ameríndio" para a grande maioria das línguas das Américas, propôs, entre outros para a América do Sul, os sub-grupos Macro-Jê ("Macro-Ge") e Equatorial. No Macro-Jê incluiu 15 famílias ou línguas: "Bororo, Botocudo, Caraja, Chiquito, Erikbatsa, Fulnio, Ge, Guato, Kaingan, Kamakan, Mashakali, Opaie, Oti, Puri, e Yabuti." (Greenberg, 1987:66). O Karirí, entretanto, foi por ele incluído no sub-grupo Equatorial, ao lado de, entre outros, o Maipure (=Aruák) e o Tupí, e considerado mais próximo deste último (Greenberg 1987:84). Terrence Kaufman apresentou o complexo Macro-Jê ("macro-Je cluster") com a seguinte constituição: família Bororo, complexo lingüístico Aimoré, língua Rikbaktsá, tronco Je (Je stock), língua Jeikó, família Kamakan, família Mashakalí, família Purí, língua Fulniô, área linguística Karajá, língua Ofayé, língua Guató (Kaufman 1994:50) e apresentou como independente a língua Karirí (Kaufman 1994:51). Lyle Campbell, na sua revisão da linguística histórica da América indígena, seguiu Kaufman no que se refere ao "complexo" Macro-Jê e à independência do Karirí (Campbell 1997:195-197). Desde 1970 tenho considerado o Karirí como uma das 12 famílias linguísticas que podem ser atribuídas ao tronco lingüístico Macro-Jê (Rodrigues 1970, 1986, 1999): I Jê, II Kamakã, III Maxakalí, IV Krenák (Botocudo), V Purí (Coroado), VI Karirí, VII Yatê, VIII Karajá, IX Ofayé, X Boróro, XI Guató, XII Rikbáktsa (a numeração é a que foi adotada em Rodrigues 1999 para referência abreviada).

\section{Evidências de parentesco genético da família Karirí com línguas de outras famílias Macro-Jê}

Em 1986 apresentei a concordância de alguns marcadores de pessoa e umas poucas correspondências lexicais do Karirí com os demais constituintes do Macro-Jê. Outras afinidades gramaticais foram objetos de comunicações em 1992 sobre um marcador Macro-Jê de posse alienável e em 2001 sobre flexão relacional no mesmo tronco linguístico. Na apresentação do Macro-Jê no livro Amazonian languages organizado por Dixon e Aikhenvald, em 1999, mostrei várias semelhanças gramaticais entre o Karirí e as demais famílias do 
tronco e também as principais diferenças tipológicas que destacam não só o Karirí, mas também o Guató. Estes dois têm as ordens VS, preposição-nome e possuído-possuidor em contraste com SV, nome-posposição e possuidorpossuído dos demais membros do tronco (Rodrigues 1999:187-190). Tais diferenças tipológicas podem servir para questionar a inclusão do Karirí e do Guató no Macro-Jê (curiosamente Greenberg e Kaufman, que mantiveram o primeiro fora deste tronco, conservaram o segundo dentro dele). Há indícios, entretanto, de que em Karirí houve inovação na ordem sintática a partir de algo mais próximo das outras famílias do Macro-Jê: quando pronominalizados seus objetos, as preposições passam a ser pospostas ( pa kri no dumarã 'foi morto por seu inimigo', mas pa kri e na 'foi morto por você', pa kri ku na 'foi morto por nós') e nas composições a ordem dos constituintes é possuidor-possuído (ipo winu 'olho do menino', mas po-ku 'líqüido do olho, lágrima'). É bastante provável que essas duas ordens em domínios restritos sejam sobrevivências de uma ordem sintática que no passado foi a mais geral.

Línguas de algumas famílias, como Boróro, Maxakalí e Jê, apresentam alguns nomes genéricos que intermedeiam a expressão de posse de certas categorias de seres, cujos nomes não podem ser determinados diretamente pelos nomes dos respectivos possuidores. O Karirí também apresenta essa característica, mas superlativamente, com 12 nomes genéricos (ou classificadores possessivos) para seres adquiridos de diversas maneiras (Rodrigues 1997:72-74, 1999:191192). Além desse, tem outro sistema de classificação, cuja base aparente é a forma geométrica dos objetos e que se manifesta por um jogo de 12 prefixos acrescentados às palavras que exprimem quantidade, dimensão, consistência ou cor (Rodrigues 1997:69-72). Outra propriedade, que o Karirí tem em grau muito superior ao de outras famílias do tronco, é a ergatividade, que se manifesta em todos os verbos transitivos e em sua nominalização, o que levou seu primeiro analista, o pe. Mamiani no século XVII, a dizer que, além dos neutros ou intransitivos, a língua Karirí só tem verbos passivos (Rodrigues 2003).

Quanto ao léxico, num conjunto preliminar de 78 séries de possíveis cognatos nas diversas famílias do tronco, o Karirí figura em 34, das quais 32 correspondem ao vocabulário básico, não cultural (Rodrigues e Cabral, no prelo). Apesar do pequeno tamanho desse conjunto, a participação do Karirí é muito significativa. Dada a dificuldade de encontrar séries de possíveis cognatos, ainda é difícil promover o tronco Macro-Jê a uma hipótese consolidada. É verdade que essa dificuldade na busca de cognatos pode ser superada com um novo esforço baseado por um lado no conhecimento ampliado do léxico de algumas famílias - recentemente foram publicados dicionários do Yatê (Caetano 2000) e do Maxakalí (Popovich e Popovich) e uma edição ampliada do Kaingang; por outro lado, foi dado início, no Laboratório de Línguas Indígenas da Universidade de Brasília, a um projeto de revisão e sistematização dos dados do século XIX e da primeira metade do século XX, sobretudo das famílias de que já morreram 
todas as línguas, como a Kamakã e a Purí. Entretanto, apesar de uma grande diversidade lexical entre as famílias consideradas, parece-me que é nos detalhes gramaticais, morfológicos e sintáticos que podemos mais imediatamente encontrar a confirmação de uma real cognação entre as 12 famílias linguísticas do Macro-Jê, que se estendem do Nordeste até o Rio Paraguai, numa distribuição que se caracteriza pela ocupação das áreas de caatingas, de campos cerrados, de campos de araucárias e de pantanal, normalmente evitando as zonas de florestas. Se pudermos concluir pela cognação, isto é, pela origem comum de todo esse enorme conjunto de línguas, teremos de admitir que é particularmente antiga, na pré-história da América do Sul, a fonte comum delas todas, a língua que chamaríamos de Proto-Macro-Jê.

\section{Particularidades da família Karirí}

Com respeito particularmente à família Karirí, é incerto ainda qual teria sido a extensão de sua área geográfica e quais os povos cujas línguas nela se integravam. Os documentos linguísticos de que dispomos são a excelente gramática e o catecismo na língua Kipeá do pe. Luís Vincêncio Mamiani, publicados em Lisboa em 1698 e 1699; o catecismo na língua Dzubukuá de fr. Bernardo de Nantes, publicado em Lisboa em 1709; pequenos vocabulários dos Cayriri de Pedra Branca (215-217) e dos Sapuyá (218-219) registrados por von Martius em 1818 (Martius 1867:215-217 e 218-219); listas de palavras lembradas pelos Karirí de Mirandela, BA, colhidas por Curt Nimuendajú na década de 1930 (manuscrito em seu acervo linguístico no Museu Nacional, ainda não examinado por nós), por Alfred Métraux na década de 1940 (Métraux 1951), por Frederico Edelweiss no fim da década de 1950 e por Maria de Lourdes Bandeira no início da de 1960 (estas duas publicadas em Bandeira 1972:114118), e ainda uma registrada em 1961 por Wilbur Pickering (Meader 1978:3840). Outras contribuições elaboram dados das fontes coloniais. Essas fontes provêm unicamente de índios Karirí das ilhas do Rio São Francisco, como os Dzubukuá entre Pernambuco e a Bahia, e de terras ao sul do São Francisco, como os de Jeru em Sergipe, os de Mirandela e os de Camamu na Bahia.

Sobre os Karirí ao norte do Rio São Francisco não há dados linguísticos, de modo que é difícil, senão impossível, para o linguista identificar outros povos indígenas como falantes de uma das línguas Karirí documentadas ou de outras línguas da mesma família genética destas. Os Karirís Velhos da Paraíba, junto aos quais os capuchinhos franceses iniciaram sua ação missionária em meados do século XVII, deviam ser afins dos que habitavam as ilhas do Rio São Francisco, para os quais se transferiu frei Martinho de Nantes depois de ter atuado oito meses entre os primeiros (Edelweiss 39). Mas para os Cariris Novos do sul do Ceará só temos essa designação, que não implica necessariamente afinidade linguística com os outros Karirí. Para os demais tapuias ao norte do São Francisco não há nenhuma informação linguística do período colonial que 
contribua para sua identificação com os Karirí.

Para alguns povos ao sul do São Francisco há, entretanto, algumas indicações de natureza cultural e minimamente linguística que permitem identificá-los como pertencentes à família Karirí. É o caso, no sertão da Bahia, dos Paiaiá e dos Morití, cujos xamãs eram chamados visamu e bisamu, respectivamente, e tinham um personagem mítico chamado Eraquizã e Araquizã, respectivamente (Leite V:273 e 277), termos que correspondem a bidzamú e Warakidzã registrados pelo pe. Mamiani no seu catecismo Kirirí.

\section{O que ainda pode ser revelado sobre a família Karirí}

Acredito que ainda possa haver documentos inéditos sobre línguas da família Karirí nos arquivos dos capuchinhos na França e informações adicionais, no arquivo dos jesuítas em Roma, às que Serafim Leite transcreveu em sua monumental História da Companhia de Jesus no Brasil.

\section{Referências}

Adam, Lucien. 1897. Matériaux pour servir à l'établissement d'une grammaire comparée des dialectes de la famille kariri. Bibliothèque Linguistique Américaine, tome XX. Paris: J. Maisonneuve, libraire éditeur.

Azevedo, Gilda Maria Corrêa de. 1965. Língua Kiriri: descrição do dialeto Kipeá. Tese de mestrado, Universidade de Brasília.

Bandeira, Maria de Lourdes. 1972. Os Kariris de Mirandela: um grupo indigena integrado. Estudos Baianos, $n^{\circ}$ 6. Salvador: Universidade Federal da Bahia.

Bernardo de Nantes, 1709. Katecismo indico da língua Kariris. Lisboa: Valentim da Costa. Edição facsimilar por Julio Platzmann: Catecismo da língua Kariris. Leipzig: Teubner, 1896.

Greenberg, Joseph H. 1997. Language in the Americas. Stanford: Stanford University Press.

Kaufman, T. 1994. The native languages of South America. In: R. E. Asher \& C. Moseley, eds., Atlas of the World's Languages, p. 46-76. London: Routledge.

Larsen, T. W. 1984. Case marking and subjecthood in Kipeá, Kirirí. Berkeley Linguistic Society Proceedings 10:189-205. Berkeley.

Leite, Serafim. 1945. História da Companhia de Jesus no Brasil, tomo V: da Baía ao Nordeste. Rio de Janeiro: Imprensa Nacional.

Loukotka, Čestmír. 1942. Klassifikation der südamerikanischen Sprachen. Zeitschrift für Ethnologie 74:1-69. Berlim.

Mamiani, Luís Vincêncio. 1698. Catecismo da doutrina christãa na lingua brasilica da nação Kiriri. Lisboa: Miguel Deslandes. Edição facsimilar por Rodolfo Garcia: Catecismo Kiriri. Rio de Janeiro: Biblioteca Nacional, 1942.

Mamiani, Luís Vincêncio. 1699. Arte de grammatica da língua brasílica da naçam 
Kiriri. Lisboa: Miguel Deslandes. (2ª ed., Rio de Janeiro: Bibliotheca Nacional, 1877).

(Mamiani, Luís Vincêncio). 1852. Grammatik der Kiriri-Sprache. Aus dem Portugiesischen des P. Mamiani übersetzt von H. C. von der Gabelentz. Leipzig: Brockhaus.

Martin de Nantes. 1952. Relation succinte \& sincere de la mission du père Martin de Nantes, Prédicateur Capucin, missionaire apostolique dans le Brésil. Edição facsimilar publicada por Frederico G. Edelweiss. Bahia : Tipografia Beneditina.

Mason, J. Alden. 1950. The languages of South American Indians. Handbook of South American Indians (Julian H. Steward, ed.), 6:157-317. Washington, D. C.: Government Printing Office.

Meader, Robert E. 1978. Índios do nordeste: levantamento sobre os remanescentes tribais do nordeste brasileiro. Série Lingüística, $n^{\circ} 8$. Brasília: Summer Institute of Linguistics.

Nogueira, Baptista Caetano d'Almeida. 1877. (Introdução à $2^{a}$. edição de Mamiani 1699, págs. IX-LXXII).

Pompeu Sobrinho, Thomas. 1948. Sistema de parentesco dos indios Cariris. Fortaleza: Editora Instituto do Ceará.

Rodrigues, Aryon D. 1942. O artigo definido e os numerais na língua Kirirí, vocabulários Português-Kirirí e Kirirí-Português. Arquivos do Museu Paranaense 2:179-212. Curitiba.

Rodrigues, Aryon D. 1947. Notas sobre o sistema de parentesco dos índios Kirirí. Revista do Museu Paulista, n. s., 2:193-205. São Paulo.

Rodrigues, Aryon D. 1970. Línguas ameríndias. Grande Enciclopédia DeltaLarousse 4034-4036. Rio de Janeiro: Delta.

Rodrigues, Aryon D. 1986. Linguas brasileiras: para o conhecimento das línguas indigenas. São Paulo: Loyola.

Rodrigues, Aryon D. 1992. Um marcador Macro-Jê de posse alienável. Anais da $44^{a}$ Renião Anual da SBPC.

Rodrigues, Aryon D. 1997. Nominal classification in Karirí. Opción, Revista de Ciências Humanas y Sociales, año 13, nº 22:65-79. Maracaibo: Universidad del Zulia.

Rodrigues, Aryon D. 1999. Karirí. The Amazonian languages (R. M. W. Dixon e A. Y. Aikhenvald, orgs.) 164-206. Cambridge: Cambridge University Press.

Rodrigues, Aryon D. 2001. Flexão relacional no tronco Macro-Jê. Boletim da ABRALIN 25:219-231. Fortaleza: Imprensa Universitária/UFC.

Rodrigues, Aryon D. 2003. Ergativité dans le nord-est brésilien: la famille kariri. Faits de langue: Méso-Amérique, Caraïbes, Amazonie (org. por Jon Landaburu e Francesc Queixalós), vol. 2:71-75. Paris.

Sá, Aluízio C. de. 2000. Dicionário Yatê-Português. Águas Belas: Ed. do autor. 